\title{
STUDY OF DEPRESSION AMONG INDIAN COLLEGE YOUTHS
}

Raghav Arora ${ }^{1}$, Lakhan Kataria², Sandip Shah ${ }^{3}$, Kajal Tanna ${ }^{4}$, Dipti Joshi' ${ }^{5}$, Anup Sinh Chhasatia ${ }^{6}$, Vidhi Patel7, Nisarg Shah ${ }^{8}$

\section{HOW TO CITE THIS ARTICLE:}

Raghav Arora, Lakhan Kataria, Sandip Shah, Kajal Tanna, Dipti Joshi, Anup Sinh Chhasatia, Vidhi Patel, Nisarg Shah. "Study of Depression among Indian College Youth". Journal of Evolution of Medical and Dental Sciences 2014; Vol. 3, Issue 02, January 13; Page: 416-421, DOI:10.14260/jemds/2014/1844

BACKGROUND: Depression, the most common disorder in psychiatry, affects about 121 million people worldwide. World Health Organization states that depression is the leading cause of disability as measured by Years Lived with Disability and the fourth leading contributor to the global burden of disease. Today, depression already is the second cause of disability adjusted life years in the age category 15-44 years. There is paucity of studies done in undergraduate students in our country.AIMS AND OBJECTIVES: To find out the prevalence of depression among undergraduate students and finding correlation between various demographic variables and depression. Cross sectional study carried on 1066 under graduate students of medical, dental, engineering and basic science branches. METHODS AND MATERIAL: CRF (containing demographic details) \& Beck Depression Inventory Scale-II were given. Students' $\geq 18$ years of all academic years were included in the study. Statistical Analysis used were multiple ANOVA test and student t test.RESULTS AND CONCLUSIONS: Prevalence of depression was found to be $26.54 \%$. More males $(29.75 \%)$ than females $(23.36 \%)$ (P value=.0001). Highest depression was found in basic Science undergraduate students (34.53\%) followed by engineering undergraduate students $(22.82 \%)$ followed by MBBS students (18.99\%) and least in dental undergraduate students (17.54\%) (P value=.00003). Students living at hostel $(24.10 \%)$ showed least depression and maximum depression was found in students living at private rooms $(31.54 \%)(\mathrm{P}$ value $=.0002)$.There is a need to diagnose and treat undergraduate students with depression at an early stage. This will help them to overcome their difficulties and lead a healthier life.

KEY WORDS: depression, undergraduate students, medical, dental, engineering, basic science.

INTRODUCTION: Depression is a major cause of morbidity worldwide ${ }^{1}$. Depressive disorder is one of the most common mental disorders, with lifetime prevalence of $16.2 \%{ }^{2}$. Depressive symptoms are widely distributed in the population and disrupt people's normal life.

In much of the developing world, however, depression is largely unexplored as a research topic. Even though the mental disorder has been recognized as a research priority, only a few numbers of relevant studies have been carried out in low- and middle-income countries 3 . Approximately $60 \%$ of these countries have contributed fewer than five articles to the international mental health indexed literature 3 .

University students are a special group of people that are enduring a critical transitory period in which they are going from adolescence to adulthood and making many major life decisions. Studies have shown that prevalence of depression among young adults seems to be increasing ${ }^{4}$ and this can lead to impairment in the development of professional, academic, and social skills 5-8.

Academic burden, though have been identified as source of depression ${ }^{9}$. Also there is a strong relationship between severity of depressive symptoms and suicidal ideation in college students ${ }^{10}$. 
It is important to study depression among university students because most lifetime mental disorders have their first onset during the typical university age ${ }^{11}$. In this vital stage, undergraduate students can face many problems, such as accommodation, interpersonal relationships, competition and difficulties in academic studies, economic stress, and struggles with making important decisions.

The primary aim was to find prevalence of depression amongst medical, dental, engineering and basic science students. The second aim was to find out relationship between various demographic variables and depression in undergraduate students.

METHODS: An analytical cross sectional study was conducted in Vadodara in five institutes. Sample comprised of - undergraduate students of medical, dental, engineering and basic science branches. Participants were selected through stratified random sampling which consisted of 4 strata (undergraduate medical and dental student, engineering and basic science). Student's $\geq 18 y e a r s$ of all academic years were included in the study. Study was carried from October 2012 to November 2013. Sample size comprised 1066 students; 531 males and 535 females. Written informed consent was taken from those who were willing to take part in the study. Standardized CRF (containing demographic details) \& Beck Depression Inventory Scale-II were given. CRF was such that it didn't reveal identity of the subject as they were not required to mention name on it. Beck Depression Inventory is a 21 item self-administered inventory where 1 statement is to be chosen from each item. Created by Dr. Aaron T. Beck, one of the most widely used instruments for measuring the severity of depression. It is designed for individuals aged 13 and over. It is a 21-question multiplechoice inventory. BDI-II demonstrates good reliability and validity in clinical and nonclinical samples 12.

Ethics: This study was carried out on undergraduate medical, dental, engineering college and basic science students of five institutes in Vadodara. It was done after taking written informed consent of the students and the colleges involved in the study. The students were not supposed to mention their names on the CRF. So there was no ethical issue involved in carrying out this study.

Statistics: 1100 students were intervened. 44 subjects were lost because of incomplete forms and not willing to take part in survey. Data thus generated was tabulated and categorized and analysis was done. Suitable statistical parameters such as mean, multiple ANOVA test and student T test to assess factors related with depression were done.

DISCUSSION: The boundary between depressive disorder and the human distress is a grey zone. The findings show the prevalence of depression (26.54\%) in undergraduate medical students. This finding is comparable with the results (31.2\%) of similar study done and published in BMJ ${ }^{13}$ but more in comparison to findings of studies from Sweden (12.9\%) ${ }^{14}$. Vaidya and Malgaonkar reported a prevalence of depression as 39.44\% among 109 medical students of T. N. Medical College, Mumbai 15. This could be either due to the different instruments used in other studies or it could be a real difference.

More males (29.75\%) than females (23.36\%) ( $\mathrm{P}=.0001)$ had depression. This was in keeping to a study recently published (October 2013) in Journal of American Medical Association which analyzed subjects using the scale that included alternative, male-type symptoms of depression found that a higher proportion of men $(26.3 \%)$ than women $(21.9 \%)(\mathrm{P}=.007)$ met criteria for depression. Analyses also using the scale that included alternative and traditional depression symptoms found that men and women met criteria for depression in equal proportions: $30.6 \%$ of 


\section{ORIGINAL ARTICLE}

men and 33.3\% of women $(\mathrm{P}=.57){ }^{16}$. However, most studies have shown that the prevalence of depression among women is between one and a half and three times more than the prevalence among men ${ }^{17-20 .}$

Maximum depression was found in basic science (34.53\%) students followed by engineering (22.82\%), MBBS students (18.99\%) dental students (17.54\%) (P=.00003). In a similar study done, non-medical students showed a higher prevalence of moderate and severe depressive symptoms than their medical student peers, although medical students reported more symptoms of mild depression ${ }^{21}$.

Higher percentage of depression was seen in students who were living in private room (31.52\%) (Students living outside hostel) followed by students living in home $(27.94 \%)$ and least in students who were living in hostel $(24.10 \%)$ ( $\mathrm{P}=.0002)$, and to our knowledge, this is only study which has tried to find and compare prevalence of depression in four education fields (medical, dental, engineering and basic science under graduate students). Students of this age group have to deal with new social demands as well as academic demands. Depression often results in lower academic performance, behaviour problem, and poor socialization. There is need to diagnose undergraduate students with depression at an early stage. If identified early can be managed by behavioral therapy, emotional support, interpersonal psychotherapy and social skill training etc.

ACKNOWLEDGMENTS: I extend my heartiest thanks to the students who took part in this study. My utmost gratitude goes to my teachers, parents, grandparents and other family members for their blessings and support. In the end, I thank the lord for sustaining me throughout this work, giving me strength and courage to complete it.

\section{REFERENCES:}

1. World Health Organization. The world health report 2001 - Mental Health: New Understanding, New Hope; 2001 [Retrieved 2008-10-19].

2. Kessler RC, Berglund P, Demler O, Jin R, Koretz D, et al. (2003) The epidemiology of major depressive disorder: results from the National Comorbidity Survey Replication (NCS-R). JAMA, 289(23), 3095-3105.

3. World Health Organization (2007) Research capacity for mental health in low- and middle income countries. Geneva: WHO.

4. Kessler RC, Walters EE (1998) Epidemiology of DSM-III-R major depression and minor depression among adolescents and young adults in the National Comorbidity Survey. Depress Anxiety, 7(1): 3-14.

5. Henderson $\mathrm{P}$, Johnson $\mathrm{MH}$. An innovative approach to developing the reflective skills of medical students. BMC Med Educ. 2002; 2:4.

6. Murdoch-Eaton DG, Levene MI. Formal appraisal of undergraduate medical students: is it worth the effort? Med Teach. 2004; 26:28-32.

7. Facundes V, Ludermir A. Common mental disorders among health care students. Rev Bras Psiquiatr. 2005; 27:194-200.

8. Kristal SL, Randall-Kristal KA, Thompson BM, Marx JA. 1998-1999 SAEM emergency medicine faculty salary and benefits survey. Acad Emerg Med. 1999.

9. Supe AN. A study of stress in medical students at Seth G.S. Medical College. J Postgrad Med 1998; 44:1-6. 
10. Garlow SJ, Rosenberg J, Moore JD, Haas AP, Koestner B, Hendin H, Nemeroff CB. Depression, desperation, and suicidal ideation in college students. Depress Anxiety. 2008; 25(6):482-8.

11. Kessler RC, Berglund P, Demler O, Jin R., Merikangas KR, et al. (2005) Lifetime prevalence and age-of-onset distributions of DSM-IV disorders in the National Comorbidity Survey Replication. Arch Gen Psychiatry, 62(6): 593-602.

12. Kühner C, Bürger C, Keller F, Hautzinger M. [Reliability and validity of the Revised Beck Depression Inventory (BDI-II). Results from German samples]. Nervenarzt. 2007 Jun; 78(6):651-6.

13. Firth J. Levels and sources in medical students. BMJ. 1986; 292:1177-80.

14. Dahlin M, Joneberg N, RunesonB. Stress and depression among medical students: a cross sectional study. MedEduc2005; 39(6):594-604.

15. Vaidya PM, Mulgaonkar KP. Prevalence of depression, anxiety and stress in undergraduate medical students and its correlation with their academic performance. Ind J Occu Therapy. 2007; 39:7-10.

16. Lisa A. Martin, Harold W. Neighbors, Derek M. Griffith. The Experience of Symptoms of Depression in Men vs. Women Analysis of the National Comorbidity Survey Replication JAMA Psychiatry. 2013; 70(10):1100-1106.

17. Kessler RC. Gender differences in major depression. In: Frank E, ed. Gender and its effects on psychopathology. Washington, DC: American Psychiatric Press, 2000:61.

18. Kohen D. Introduction. In: Kohen D, ed. Women and mental health. Philadelphia: Routledge, 2000:1.

19. Angst J. Epidemiology of depression. In: Honig A, Van Praag HM, eds. Depression: Neurobiological, psychopathological and therapeutic advances. New York: John Wiley \& Sons, 1997:17.

20. Shaw J, Kennedy SH, Joffe RT. Gender differences in mood disorders: A clinical focus. In: Seeman MV, ed. Gender and psychopathology. Washington, DC: American Psychiatric Press, 1995:91.

21. Honney K, Buszewicz M, Coppola W, Griffin M. Comparison of levels of depression in medical and non-medical students. Clin Teach. 2010 Sep; 7(3):180-4. 


\begin{tabular}{|c|c|c|c|c|c|c|}
\hline Group & Type & \multirow{2}{*}{\multicolumn{2}{|c|}{$\begin{array}{c}\text { Frequency n (\%) } \\
1066 \text { Age: } 19 \text {-28 Mean: } \\
\text { 19.12 SD: } 1.41\end{array}$}} & \multirow{2}{*}{$\begin{array}{c}\text { Type of Depression } \\
\text { category }\end{array}$} & \multirow[b]{2}{*}{$\mathbf{n}$} & \multirow[b]{2}{*}{$p$ value } \\
\hline \multicolumn{2}{|c|}{ Age } & & & & & \\
\hline \multirow{6}{*}{ Gender } & \multirow{3}{*}{ Male } & \multirow{3}{*}{531} & \multirow{3}{*}{49.81} & Normal & 373 & \multirow{6}{*}{0.0001} \\
\hline & & & & Moderate & 106 & \\
\hline & & & & Significant & 52 & \\
\hline & \multirow{3}{*}{ Female } & \multirow{3}{*}{535} & \multirow{3}{*}{50.18} & Normal & 410 & \\
\hline & & & & Moderate & 91 & \\
\hline & & & & Significant & 34 & \\
\hline \multirow{12}{*}{$\begin{array}{l}\text { Educational } \\
\text { Field }\end{array}$} & \multirow{3}{*}{ Basic Science } & \multirow{3}{*}{475} & \multirow{3}{*}{44.55} & Normal & 311 & \multirow{12}{*}{0.00003} \\
\hline & & & & Moderate & 109 & \\
\hline & & & & Significant & 55 & \\
\hline & \multirow{3}{*}{ Dental } & \multirow{3}{*}{171} & \multirow{3}{*}{16.04} & Normal & 141 & \\
\hline & & & & Moderate & 25 & \\
\hline & & & & Significant & 5 & \\
\hline & \multirow{3}{*}{ Engineering } & \multirow{3}{*}{241} & \multirow{3}{*}{22.6} & Normal & 186 & \\
\hline & & & & Moderate & 42 & \\
\hline & & & & Significant & 13 & \\
\hline & \multirow{3}{*}{ Medical } & \multirow{3}{*}{179} & \multirow{3}{*}{16.79} & Normal & 145 & \\
\hline & & & & Moderate & 21 & \\
\hline & & & & Significant & 13 & \\
\hline \multirow{9}{*}{ Residency } & \multirow{3}{*}{ Home } & \multirow{3}{*}{501} & \multirow{3}{*}{46.99} & Normal & 361 & \\
\hline & & & & Moderate & 98 & \\
\hline & & & & Significant & 42 & \\
\hline & & & & Normal & 359 & \\
\hline & Hostel & 473 & 44.37 & Moderate & 82 & 0.0002 \\
\hline & & & & Significant & 32 & \\
\hline & & & & Normal & 63 & \\
\hline & Private Room & 92 & 8.63 & Moderate & 17 & \\
\hline & & & & Significant & 12 & \\
\hline
\end{tabular}




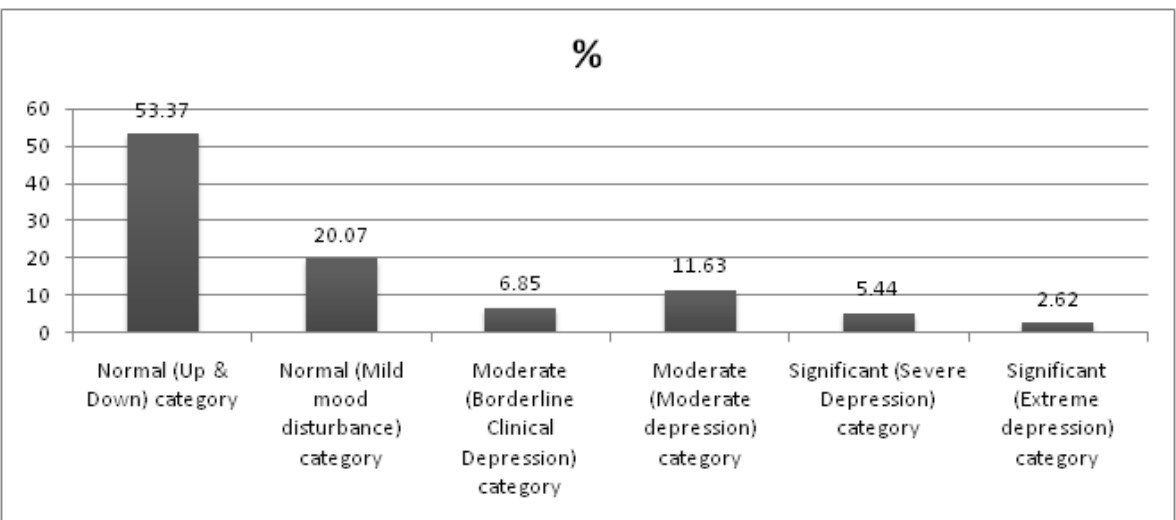

Figure/Graph depicts prevalence of depression according to different categories

\section{AUTHORS:}

1. Raghav Arora

2. Lakhan Kataria

3. Sandip Shah

4. Kajal Tanna

5. Dipti Joshi

6. Anup Sinh Chhasatia

7. Vidhi Patel

8. Nisarg Shah

\section{PARTICULARS OF CONTRIBUTORS:}

1. $3^{\text {rd }}$ Year Resident, Department of Psychiatry, Smt. B.K. Shah Medical Institute \& Research Centre, Sumandeep Vidyapeeth, Piparia, Waghodia Road, Vadodara, Pincode - 391760.

2. Associate Professor, Department of Psychiatry, Smt. B.K. Shah Medical Institute \& Research Centre, Sumandeep Vidyapeeth, Piparia, Waghodia Road, Vadodara, Pincode - 391760.

3. Professor \& Head of Department, Department of Psychiatry, Smt. B.K. Shah Medical Institute \& Research Centre, Sumandeep Vidyapeeth, Piparia, Waghodia Road, Vadodara, Pincode 391760.

4. Assistant Professor, Department of Psychiatry, Smt. B.K. Shah Medical Institute \& Research Centre, Sumandeep Vidyapeeth, Piparia, Waghodia Road, Vadodara, Pincode - 391760.

5. Clinical Psychologist, Department of Psychiatry, Smt. B.K. Shah Medical Institute \& Research Centre, Sumandeep Vidyapeeth, Piparia, Waghodia Road, Vadodara, Pincode 391760.
6. $2^{\text {nd }}$ Year Resident, Department of Psychiatry, Smt. B.K. Shah Medical Institute \& Research Centre, Sumandeep Vidyapeeth, Piparia, Waghodia Road, Vadodara, Pincode 391760.

7. $2^{\text {nd }}$ Year Resident, Department of Psychiatry, Smt. B.K. Shah Medical Institute \& Research Centre, Sumandeep Vidyapeeth, Piparia, Waghodia Road, Vadodara, Pincode 391760.

8. $2^{\text {nd }}$ Year Resident, Department of Psychiatry, Smt. B.K. Shah Medical Institute \& Research Centre, Sumandeep Vidyapeeth, Piparia, Waghodia Road, Vadodara, Pincode 391760 .

\section{NAME ADDRESS EMAIL ID OF THE CORRESPONDING AUTHOR:}

Dr. Raghav Arora, Department of Psychiatry, Smt. B.K. Shah Medical Institute \& Research Centre, Sumandeep Vidyapeeth, Piparia, Waghodia Road, Vadodara, Pincode - 391760.

Email-drraghav_arora@yahoo.com

Date of Submission: 11/12/2013. Date of Peer Review: 12/12/2013. Date of Acceptance: 28/12/2013. Date of Publishing: 10/01/2014 